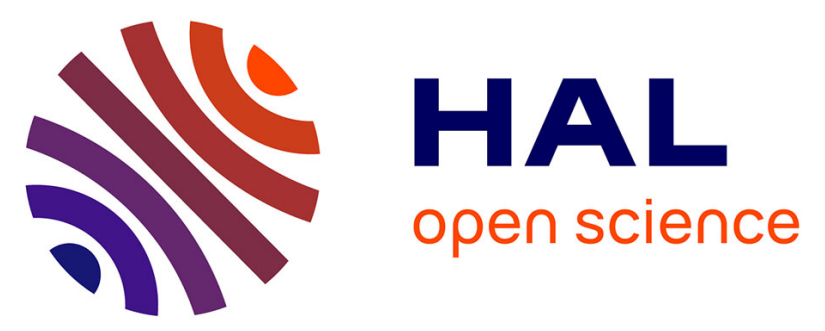

\title{
Mechanical behaviour of a $\beta$-TCP ceramic with a random porosity: Study of the fracture path with X-ray tomography
}

Clémence Petit, Sylvain Meille, Eric Maire, Solene Tadier, Jérôme Adrien

\section{- To cite this version:}

Clémence Petit, Sylvain Meille, Eric Maire, Solene Tadier, Jérôme Adrien. Mechanical behaviour of a $\beta$-TCP ceramic with a random porosity: Study of the fracture path with X-ray tomography. Journal of the European Ceramic Society, 2016, 36 (13), pp.3225-3233. 10.1016/j.jeurceramsoc.2016.05.001 . hal-03123645

\section{HAL Id: hal-03123645 \\ https://hal.science/hal-03123645}

Submitted on 28 Jan 2021

HAL is a multi-disciplinary open access archive for the deposit and dissemination of scientific research documents, whether they are published or not. The documents may come from teaching and research institutions in France or abroad, or from public or private research centers.
L'archive ouverte pluridisciplinaire HAL, est destinée au dépôt et à la diffusion de documents scientifiques de niveau recherche, publiés ou non, émanant des établissements d'enseignement et de recherche français ou étrangers, des laboratoires publics ou privés. 
Mechanical behaviour of a $\beta$-TCP ceramic with a random porosity: study of the fracture path with X-ray tomography

Clémence Petit ${ }^{1}$, Sylvain Meille ${ }^{1}$, Eric Maire ${ }^{1}$, Solène Tadier ${ }^{1}$, Jérôme Adrien ${ }^{1}$

${ }^{1}$ INSA de Lyon, MATEIS CNRS UMR5510

Université de Lyon

69621 VILLEURBANNE, France

Corresponding author: sylvain.meille@insa-lyon.fr

Keywords: Calcium phosphate, Porous ceramics, X-ray Tomography, Mechanical behaviour

\begin{abstract}
Macro-porous $\beta$ Tricalcium Phosphate $(\beta-\mathrm{TCP})$ samples were produced by a sacrificial template method with polyethylene (PE) beads used as porogens. X-ray computed tomography was used at two resolutions to characterize the structure at the scale of the sample and at the scale of the microstructure. For the latter scale, the sample was scanned in a so called "local" tomography mode, in which the specimen is placed close to the X-ray source. These images enabled to observe some details which were not visible at a lower resolution. Then, an ex situ uniaxial compression test was performed and the deformation of the sample was followed at low resolution with the tomograph. The 3D images showed the importance of clusters of macro-pores on the crack initiation and propagation in ceramics with a random porosity.
\end{abstract}




\section{Introduction}

Porous calcium phosphate scaffolds are the most widely used materials for bone substitution [1, 2, 3]. They are aimed at favouring new bone growth thanks to their porous structure and resorption process in the body through physico-chemical dissolution and cell driven resorption. Intrinsic advantages of these compounds are their chemical composition, which is close to the mineral part of bone, and their high volume fraction of pores. It is generally established that a high volume fraction of interconnected porosity is necessary to favour bone colonization and vascularization of the scaffolds, through the circulation of fluids (e.g. blood) and cells access into the scaffold. Different studies demonstrated that scaffolds need interconnected macro-pores with a diameter larger than 100 $\mu \mathrm{m}[4,5]$ and interconnection size of above $10 \mu \mathrm{m}$. The presence of a micro-porosity with a size ranging from the nanometer to the micrometer is also important to favour the bone cell attachment $[6,7]$ and to tailor the resorption in vivo.

Nevertheless, the presence of pores in the sample has a detrimental effect on its mechanical strength. The respective influence of macro and micro- pores on strength of porous ceramics with a random macroporosity has been largely described and modelled $[5,8,9]$. Usually, the theoretical basis of the models is based on minimum solid area models developed by Rice [10], or on cellular models developed by Gibson and Ashby [11]. These models assume a geometric arrangement of solid elements or of pores in a volume. These approaches have some limits as the random character of the porosity is not taken into account in the analytical models. It has been shown for instance that the agglomeration of macropores in the form of "clusters" [8] can be at the origin of fracture in brittle porous ceramics tested in bending. When tested in compression (a loading mode which is common for bone substitutes in service), porous ceramics can show a purely brittle behaviour or a damage behaviour with multiple cracking during a stress plateau after the elastic domain. A transition from a brittle to a damage behaviour has been observed when the volume fraction of pores increases [12]. 
However, the determination of the fracture sequence (location of the initiation, coalescence of microcracks into macro-cracks) is still lacking due to the difficulty to suppress catastrophic crack propagation of the samples.

The objective of this study is to have a new insight of the fracture of highly porous ceramics made of calcium phosphate in uniaxial compression, by following the crack propagation using X-ray tomography and ex situ mechanical loading.

Samples were processed through a sacrificial template using spherical pore formers with two size distributions to generate pores with different sizes. The aim was to obtain a macro-porous sample with a high volume fraction of homogeneously distributed macro-pores. Moreover, a limited volume fraction of smaller pores were intentionally added in the solid phase of the sample in order to study the their relative influence on the macroscopic mechanical behaviour. The main advantage of the sacrificial template process is the possibility to control precisely the pore size and shape, as already largely demonstrated in the literature $[13,14,15]$. Samples were then scanned with X-ray computed tomography, which has become one of the most popular means of characterization of highly porous materials [16]. This non-destructive technique allows providing three dimensional information with typical resolutions of few microns. Microstructural information within the solid phase can gather with the so-called local tomography. In this mode, the sample is placed near the X-ray source and a high resolution image of the irradiated part of the sample is obtained. X-ray tomography was also used to follow a compression test through ex situ incremental uniaxial loadings.

\section{Materials and methods}

\subsection{Fabrication of the $\beta$-TCP samples}


$\beta$-TCP powder was synthesized in the laboratory to make sure that chemical composition and powder granulometry were controlled. Two commercial polyethylene powders were used as pore formers.

\subsubsection{Synthesis and characterization of the $\beta$-TCP powder}

$\beta$-TCP powder was synthesized by a solid state reaction from two precursors: $\mathrm{CaCO}_{3}$ (Sigma Aldrich, batch SZBC0590V, purity > $99 \%$ ) and $\mathrm{CaHPO}_{4}($ Sigma Aldrich, batch 051M0120V, purity $98 \%)$. The two powders were first dried to remove humidity. Then, stoichiometric amounts of the two reagents were weighed and mixed with zirconia balls in a mixer (Turbula, Wab, Switzerland) during 25 minutes. This duration was chosen to avoid formation of aggregates. Then, a calcination treatment was performed at $1050^{\circ} \mathrm{C}$ during 4 hours to allow the formation of $\beta$-TCP, following the equation (1). The heating rate was $2.5^{\circ} \mathrm{C} / \mathrm{min}$ and the cooling rate was $5^{\circ} \mathrm{C} / \mathrm{min}$.

$$
2 \mathrm{CaHPO}_{4}+\mathrm{CaCO}_{3} \rightarrow \mathrm{Ca}_{3}\left(\mathrm{PO}_{4}\right)_{2}+\mathrm{CO}_{2}+\mathrm{H}_{2} \mathrm{O}
$$

The powder was ball-milled in a milling jar with alumina balls and ethanol during 20 minutes to remove the aggregates. After ball-milling, granulometric distribution was measured by laser diffraction granulometry in dry conditions (Mastersizer, Malvern Instruments, UK). Ball milling allowed decreasing the values of $d_{10}, d_{50}$ and $d_{90}(10 \%, 50 \%$ and $90 \%$ of the cumulative volume of particles had a smaller diameter than these numbers, see table 1).

\subsubsection{Characterization of the pore formers}

Two polyethylene (PE) powders were used as pore formers. The macro-pores were created from a commercial powder hereafter referred to as macro PE (Clariant SpA Licowax ${ }^{\circledR}$ Fine Grain, Switzerland). It was sieved to select spheres with a diameter between $150 \mu \mathrm{m}$ and $300 \mu \mathrm{m}$. The 
smaller pores were created by another powder with a diameter between 10 and $27 \mu \mathrm{m}$ hereafter referred to as micro PE (Cospheric LLC, USA). The granulometric distributions of the two PE powders (fig. 1) and SEM images (fig. 2) show that the two powders had clearly two different sizes and distributions. The macro PE powder size distribution has a peak value for a size of $275 \mu \mathrm{m}$ whereas the peak value of the micro PE is reached for a size of $26 \mu \mathrm{m}$. SEM images of the macro PE beads show the presence of smaller spheres which seemed to be agglomerated to the largest ones (fig. 2a).

\subsubsection{Fabrication of the sintered samples}

$\beta$-TCP sintered samples were fabricated with a target total volume fraction of macro-pores of $60 \%$ and a target total volume fraction of micro-pores of $2 \%$. Adequate quantities of components were calculated considering a cylindrical matrix with a diameter of $10 \mathrm{~mm}$ and a height of $10 \mathrm{~mm}$ (Eurolabo, France). The $\beta$-TCP powder and the PE beads were mechanically mixed (Turbula, Wab, France) during 20 minutes to obtain a homogeneous dispersion of the organic phase in the ceramic powder. Cylinders were obtained by uniaxial compression (Sodemi, France) at $30 \mathrm{MPa}$. $\beta$-TCP samples were then heat treated in a conventional furnace (Nabertherm, Germany) with a first debinding step at $600{ }^{\circ} \mathrm{C}$ for 7 hours and a second sintering step at $1200^{\circ} \mathrm{C}$ during 10 hours. This temperature was chosen to avoid the formation of the $\alpha$-TCP phase. The heating rate was of $2^{\circ} \mathrm{C} / \mathrm{min}$ for the debinding step and $2.5^{\circ} \mathrm{C} / \mathrm{min}$ for the sintering step. Once sintered, the samples were cut to obtain a square prism shape. The sample considered hereafter was a square prism shape sample with dimensions of $4.2 \mathrm{~mm}$ (in direction 3 which is the compaction direction during fabrication and the loading direction during compression), $5.4 \mathrm{~mm}$ and $5.3 \mathrm{~mm}$ (length and width, directions 1 and 2 respectively).

\subsubsection{Characterization of the calcium phosphate phase by X-ray Diffraction (XRD)}


The phase composition of the sintered samples was analysed by XRD (Brueker D 8 Advance, Karlsruhe, Germany) with $\mathrm{Cu}$ Ka radiation $(\lambda=0.15406 \mathrm{~nm})$. Collection was done with angular range from $2 \theta=10^{\circ}$ to $60^{\circ}$ with a Lynxeye detector. The peaks were identified on the resulting patterns by comparison with Joint Committee of Powder Diffraction Standard (JCPDS) files. As expected, the $\beta$ TCP phase was the only identified phase in the sample.

\subsubsection{Characterization of the samples}

The geometric relative density was calculated from the weight and the dimensions of the sample, considering a density of $3.14 \mathrm{~g} . \mathrm{cm}^{-3}$ for a fully dense and pure $\beta$-TCP sample.

One face of the samples was carefully polished down to $1 \mu \mathrm{m}$ with a diamond paste. After polishing, the sample was etched by a thermal treatment at $1100^{\circ} \mathrm{C}$ during 1 hour. Then, the sample was observed with scanning electron microscopy (SEM, ZEISS, SUPRA VP55, Philips) at a voltage of $1 \mathrm{kV}$ without metallization.

\subsection{X-ray tomography}

A laboratory X-ray tomograph (Phoenix vTomeX / X ray, Germany) described in [17] was used to scan the sample. The tomograph was operated at $80 \mathrm{kV}$ and $180 \mu \mathrm{A}$ with no filter on the X-ray tube. The whole sample was scanned at a resolution of $15 \mu \mathrm{m}$. The 3D final images were then obtained by a standard filtered back projection algorithm implemented in the software coupled to the tomograph [18]. In order to observe the finer details of the microstructure, local tomography was subsequently used [19]. For this purpose, the sample was placed closer to the X-ray source. Only a part of the sample was irradiated by X-rays under all the viewing angles as the field of view of the detector was smaller than the size of the sample. Some authors have shown that the reconstruction is possible when the sample is homogeneous outside of the field of view of the detector [20, 21]. As a consequence, 
the reconstructed image by local tomography has a lower signal to noise ratio than in conventional tomography. Due to their low density, the porous samples are particularly adapted to local tomography [19]. Using this mode, a high resolution reconstruction of the irradiated part of the sample could be obtained (voxel size of $3 \mu \mathrm{m}$ ). To scan another part of the sample, it was then sufficient to physically displace the specimen on the rotating stage. Finally, 8 images were scanned, each one representing a part of the sample.

Ex situ compression tests were performed to follow the crack initiation and propagation in the sample. The considered sample was loaded outside of the tomograph thanks to a BOSE Electroforce 3200 machine (Prairie Valley, USA) equipped with a $200 \mathrm{~N}$ load cell and a high resolution capacitive displacement sensor and scanned in the tomograph at different levels of strain. The test was displacement controlled with a load ramp of $0.03 \mathrm{~mm} \cdot \mathrm{min}^{-1}$. To avoid contact damage, the two faces in contact with the loading platens were embedded with paraffin wax.

\subsection{Image processing and analysis}

Image processing of the 3D images obtained by tomography was performed using Image J software [22]. The high resolution images of the initial sample were processed to improve the image quality: adjustment of contrast and brightness, application of median filtering over neighbours of two voxels and thresholding to separate the pores from the solid phase.

Then, the thresholded high resolution images were used to perform different morphological characterizations. The principle of the measurements is explained in details in [23].

The relative density was determined as the ratio of the number of voxels belonging to the solid phase compared to the total number of voxels.

The distributions of the pore size and of the cell wall thickness were measured by a granulometry 
technique comparable to sieving of a powder [23]. It consists in the application of a series of erosion and dilation operations to the studied phase of the image. A histogram giving the pore size or the cell wall thickness distribution is then obtained.

\section{Results}

\subsection{Characterization of the architecture of the sample}

Fig. 3a presents a 3D visualization from tomographic image obtained at low resolution $(15 \mu \mathrm{m})$ showing the spherical macro-pores created by the debinding of the macro PE powder. A tomographic slice is also shown at the two resolutions used during this study: voxel size of $15 \mu \mathrm{m}$ (fig. $3 \mathrm{~b}$ ) and of $3 \mu \mathrm{m}$ (fig. 3c). The two images highlight the difference between the two resolutions. The small pores created by the micro PE powder and other defects (clusters of pores or small cracks linking two pores) are only visible thanks to local tomography (fig. 3d). These small cracks can be attributed to residual stresses during cooling to room temperature after sintering. The possibility to obtain pores with desired shape and size thanks to sacrificial template method is confirmed by the images from two resolutions. The images also show a random distribution of the pores with a rather good homogeneity despite the presence to a certain extent of some agglomerates.

The relative density calculated by $3 \mathrm{D}$ image analysis on the volume is $0.52( \pm 0.02)$. The relative density distribution along the principal axes is shown in fig. 4. It varies along each direction between 0.45 and 0.58 . This variation is attributed to the random distribution of the pores in the sample. The apparent geometric density, calculated considering the solid phase as pure $\beta$-TCP, is $0.29( \pm$ ?). The difference between the apparent density and the relative density from $3 \mathrm{D}$ image is investigated in a following section. 
Cell wall thickness and pore size distribution obtained by $3 \mathrm{D}$ granulometry are given in fig. 5a and b. Cell wall thickness is comprised between 10 and $150 \mu \mathrm{m}$. The main peak of pore size distribution around $156 \mu \mathrm{m}$ corresponded to the macro-pores formed by the removal of macro PE pore formers. A second small peak around $18 \mu \mathrm{m}$ matched the size of micro PE pore formers, which were burned out. Between these two peaks, the curve indicates the presence of some pores with an intermediate size between 20 and $100 \mu \mathrm{m}$. These values could correspond to the interconnections between the macro-pores which are visible in tomographic images (fig. 3). These distributions confirmed that the $\beta$-TCP samples contained thin cell walls with two pore size distributions.

\subsection{Characterization of the microstructure of the solid phase}

As already mentioned, a difference is noted between the volume fraction of pores calculated by 3D image analysis with high resolution images $(0.48 \pm 0.02)$ and the value obtained by measurement of the sample dimensions $(0.71 \pm$ ?). Fig. 6 a is a SEM image of the solid phase of the sample. Residual micro-pores with a size of few microns are visible, due to incomplete sintering of the ceramic phase. SEM images showing the solid phase were processed by thresholding and a volume fraction of residual micro-pores in the micro-porous solid phase of $0.30( \pm$ ?) was computed by $2 \mathrm{D}$ image analysis. Therefore, the volume fraction of residual micro-pores in the whole sample with 0.48 of porous phase is estimated as $0.16 \pm$ ?. This value corresponds approximately to the difference between the two previous values of volume fraction of pores $(0.20)$. The difference between the two values can be caused by the uncertainties of the measurements of the volume of samples (geometric density), as well as of the fraction of pores by 2D image analysis on SEM images. Magnified SEM image (fig. 6b) shows well sintered grains with irregular shape. The grain size of the $\beta$-TCP phase measured on SEM images is $2.3 \pm 0.4 \mu \mathrm{m}$. This size is slightly larger than the $\beta$-TCP powder particle size 
suggesting a bit of coarsening during sintering.

\subsection{Ex situ compression test}

Fig. 7a presents the successive stress/strain curves obtained for the sample during the ex situ test. The black curve corresponds to the final loading until fracture. The other curves correspond to six loadings interrupted to scan the sample at different damage levels (for increasing values of the maximum applied strain). The beginning of the stress/strain curve is also shown in fig. $7 \mathrm{~b}$. The shape of the curve and the evolution of the stiffness will be discussed in the next section.

Fig. 8 presents two loading and unloading cycles undergone by the sample at low strains. A large difference can be noted in the stiffness of the samples during loading and unloading, with a much larger stiffness at the onset of unloading. The stiffness during unloading is shown to increase with the cycle number. Loading-unloading hysteresis is also noted, as well as an irreversible residual strain at the end of the unloading steps.

The compression strength is considered as the maximum stress reached during the test and the value is $4.1 \mathrm{MPa}$. Table 2 summarises the results and presents results from the literature. The effective Young's modulus can be calculated from different parts of the stress/strain curve. The different values obtained and data from literature are summarised in table 3. The values of Young's modulus obtained from literature were measured during a loading cycle of a stress/strain curve. For this reason, they are closer to the experimental value calculated from the loading curve.

The stress/strain curve reveals a typical behaviour of a cellular ceramic with a linear increase of the stress followed by a stress plateau [12]. The test ended by a progressive collapse of the sample. To illustrate the crack propagation in the sample, 3D views of samples could have led to a too complex rendering and crack propagation would have not been clearly visible. For this reason, slices 
perpendicular to the loading axis illustrating important points are presented. Fig. 9 shows a slice of the sample after the sixth loading illustrating the propagation of cracks during the test. Cracks are visible propagation along different directions. Fig. 10a and $\mathrm{b}$ show other slices after respectively the first and the sixth loading. The frames present a magnified view of a part of the image where a crack propagated mainly through the macro-pores and especially through the clusters of macro-pores (see especially the frame in fig. 10b). In our work, the initial crack propagation always occurs at the surface of the sample, linking its exterior surface to a close macropore, as illustrated in fig. 10a.

\section{Discussion}

Despite the absence of binders in the fabrication, a sintered sample with a volume fraction of pores of $71 \%$ was obtained with no residual powder. The homogeneous dispersion of the pores proved that the ceramic powder and the PE beads were correctly mixed before uniaxial compression. Moreover, our fabrication process allows creating interconnections between the macro-pores. The presence of these interconnections is an important requirement for bone substitutes $[1,2,5,6]$. The spherical shape of the pores shows that the uniaxial compression did not cause a crushing of the PE beads. A certain degree of non-linearity is observed in the loading curves with an increase of the axial stiffness (fig. 7b) as the applied stress increases. This has already been largely observed during compression test of porous samples [27] or rocks [28]. The increase of stiffness with increasing applied load has been attributed to a progressive closure of some micro-cracks favourably orientated relatively to the loading direction. This type of micro-cracks is present in our sample as it is visible with local tomography (fig. 3d). The fact that a non-linear stress strain curve is observed for all the loadings shows that non-linear mechanisms such as crack closure are present. It has to be noted that the samples were removed from the testing machine at the end of each loading cycle for scanning and they were reloaded after each scan. Possible crack re-opening could then occur during sample manipulation 
between scans. It is also important to note that the testing conditions can also have an influence on the measured stiffness, especially on highly porous samples with non perfectly flat surfaces. In our samples, the two faces in contact with the compression platens were embedded with paraffin wax to avoid material densification during polishing and to avoid local brittle fracture during compression loading. The increase in stiffness at the onset of loading, noted in fig. 8 for the first loading, can also be related to a better contact conformation between the samples and the platens.

The apparent stiffness is shown to increase from loading to unloading part of a cycle (see fig. 8) [27, 28]. At the onset of unloading, the stress strain curve is linear: no mechanism associated to non linearity is active. Then, the axial stiffness slowly decreases possibly due to the opening of the closed cracks and/or sliding of the closed cracks faces $[27,28]$. This axial stiffening of the unloading curve can explain the high value obtained for the effective Young's modulus calculated during unloading, in comparison with the literature values (see table 2). As visible in fig. 8, the stiffness at the onset of the unloading curves increases with the loading/unloading cycle number. This can also be linked to an increased crack closure at higher applied strains.

After the four first loadings, the stiffness decreases with the increase of stress (see Fig. 7). This can be interpreted by a sufficient crack propagation in the material that starts to have an impact on the macroscopic stiffness of the sample.

At high applied strains, the stress/strain curve are followed by a stress plateau is typical of a cellular ceramic with a damageable behaviour $[11,12]$, as already observed in a macroporous alumina with a macro-porosity fraction above 50\% [12]. Therefore, the cellular-like behaviour of our sample is expected to be due to the high volume fraction of pores. The densification stage often observed for metal or polymer-based cellular materials is not observed in this case because the sample collapses before this step.

For the first time according to our knowledge, the propagation of cracks in compression in a brittle porous ceramic is observed at different steps of loading with X-ray tomography. The initiation of 
cracking occurred before the stress plateau and can therefore not be detected with the stress-stress curve. Cracks initiate near macro-pores on the side of the sample, at different locations inside the sample. Then, they propagate especially by linking macro-pores and more specifically through clusters of macro-pores. These observations confirm the hypothesis developed by different authors $[8,9,10,29]$ about the influence of the clusters of macro-pores. A more periodic structure (i.e., with regularly spaced macropores and single peak-distributed solid wall thicknesses) should lead to improved fracture properties. The benefit of having a homogeneous distribution of pores on the mechanical strength in compression has already been already noted for anisotropic porous ceramics processed by freeze-casting [30] or robocasting [31].

The influence of the small defects intentionally added in the solid phase seems to be different. Some models have already been developed to quantify the influence of the pores when different pore size distributions are present $[8,9]$. Careful observation of the 3D images of the ex situ test seems to show that the cracks path do not cross the smaller pores. This leads us to conclude the most critical features for crack propagation in our samples are the macro-pores and their clusters. It has to be noted that the volume fraction of small pores added in the solid phase is relatively limited ( 2 vol\%) and that our samples contain residual micro-pores left by sintering which could not be detected by local tomography due to the voxel size of $3 \mu \mathrm{m}$. The relative influence as stress concentrators of small pores in the solid walls is certainly limited by the large presence of these interconnected residual pores. Other tests on samples with a higher volume fraction of small pores and lower amount of residual pores left after uncomplete sintering are necessary to investigate further the role of small porosity on the mechanical behaviour of porous ceramics. The use of synchrotron tomograph or laboratory tomograph with better resolution would then be necessary to check their influence the crack initiation and propagation.

\section{Conclusion}


This study focused on the mechanical behaviour of a cellular ceramic with a stochastic microstructure. $\beta$-TCP samples were fabricated by a sacrificial template method contained three types of pores: a macro-porosity defining the architecture of the sample with a size of 100-300 $\mu \mathrm{m}$, smaller pores with a size of 10-30 $\mu \mathrm{m}$ and residual micro-pores having a size of few microns due to incomplete sintering. This paper proposes to use X-ray tomography to study the structure and mechanical properties of a porous ceramic. The structural characterization is performed by a combination of scanning at two resolutions to obtain information at different scales. The mechanical behaviour was analysed with 3D images scanned during an ex situ test. The 3D images of the test show the initiation and propagation of multiple small cracks though the macro-pores and especially through the aligned and overlapping pores (clusters of macro-pores). This feature has already been hypothesized by some authors [8, 9] but has not been observed yet. For the first time, our study allows the observation of the crack initiation and propagation in a porous ceramic thanks to tomographic images. Therefore, we show Xray tomography is a powerful tool to characterize the structural and mechanical properties of porous ceramics. Thanks to the ex situ test, the cracks propagation is followed step by step. The 3D images prove the important influence of the macro-pores on the crack initiation and propagation. However, the smaller pores intentionally added do not seem to influence the crack path. The residual micropores are too small to be observed by the tomographic images with voxel sizes of 3 and $8 \mu \mathrm{m}$. In addition, the presence of a relatively important residual porosity left after uncomplete sintering makes difficult to conclude about their influence on the compression test.

Other compression tests with other samples with a higher volume fraction of small pores and a low amount of residual micro-pores should be necessary to better understand their role. For this purpose, the sintering conditions could be optimized to remove the residual micro-pores. Furthermore, a better characterization could be performed with 3D images with a higher resolution (voxel size lower than $1 \mu \mathrm{m})$. 


\section{References}

[1] M. Bohner, Calcium orthophosphates in medicine: from ceramics to calcium phosphate cements, Int. J. Care Injured, 31 (2000) SD37-SD47.

[2] M.M. Stevens, Biomaterials for bone tissue engineering, Mater. Today 11 (2008) 18-25.

[3] A.J. Wagoner Johnson, B.A. Herschler, A review of the mechanical behavior of CaP and $\mathrm{CaP} /$ polymer composites for applications in bone replacement and repair, Acta Biomater. 7 (2011) $16-30$.

[4] S.F. Hulbert, S.J. Morrison, J.J. Klawitter, Tissue reaction to three ceramics of porous and nonporous structures, J. Biomed. Mater. Res. 6 (1972) 347-374.

[5] D.M. Liu, Influence of porosity and pore size on the compressive strength of porous hydroxyapatite ceramic, Ceram. Int. 23 (1997) 135-139.

[6] A. Bignon, J.J. Chouteau, J. Chevalier, G. Fantozzi, J.P. Carret, P. Chavassieux, G. Boivin, M. Melin, D. Hartmann, Effect of micro- and macroporosity of bone substitutes on their mechanical properties and cellular response, J. Mater. Sci. Mater. Med. 14 (2003) 1089-1097.

[7] K.A. Hing, B. Annaz, S. Saeed, P.A. Revell, T. Buckland, Microporosity enhances bioactivity of synthetic bone graft substitutes, J. Mater Sci. Mater. Med. 16 (2005) 467-475.

[8] F. Tancret, J.-M. Bouler, J. Chamousset, L.-M. Minois, Modelling the mechanical properties of microporous and macroporous biphasic calcium phosphate bioceramics, J. Eur. Ceram. Soc. 26 (2006) 3647-3656.

[9] F. Pecqueux, F. Tancret, N. Payraudeau, J.-M. Bouler, Influence of microporosity and macroporosity on the mechanical properties of biphasic calcium phosphate bioceramics: modelling and experiment, J. Eur. Ceram. Soc. 30 (2010) 819-829.

[10] R.W. Rice, Porosity of ceramics, New York: Marcel Dekker, 1998, 542 p. 
[11] L.J. Gibson, M.F. Ashby, Cellular Solids: Structure and Properties, 2nd ed., Cambridge University Press, Cambridge, 1997.

[12] S. Meille, M. Lombardi, J. Chevalier, L. Montanaro, Mechanical properties of porous ceramics in compression: on the transition between elastic, brittle, and cellular behaviour, J. Eur. Ceram. Soc. 32 (2012) 3959-3967.

[13] E. Chevalier, D. Chulia, C. Pouget, M. Viana, Fabrication of porous substrates: A review of processes using pore forming agents in the biomaterial fields, J. Pharm. Sci. 97 (2008) 1135-1154.

[14] M. Descamps, T. Duhoo, F. Monchau, J. Luc, P. Hardouin, J.C. Hornez, A. Leriche, Manufacture of macroporous $\beta$-tricalcium phosphate bioceramics, J. Eur. Ceram. Soc. 28 (2008) 149-157.

[15] Y. Liu, J.H. Kim, D. Young, Novel template-casting technique for fabricating $\beta$-tricalcium phosphate scaffolds with high interconnectivity and mechanical strength and in vitro cell responses, J. Biomed. Mater. Res. A 92 (2010) 997-1006.

[16] E. Maire, X-ray tomography applied to the characterization of highly porous materials, Annu. Rev. Mater. Res. 42 (2012) 7.1-7.16.

[17] J.-Y. Buffière, E. Maire, J. Adrien, J.-P. Masse, E. Boller, In situ experiments with X ray tomography: an attractive tool for experimental mechanics, Exp. Mech. 50 (2010) 289-305.

[18] Kak AC, Slaney M (1988) Principles of computerized tomographic imaging. IEEE, New York.

[19] T. Zhang, E. Maire, J. Adrien, P.R. Onck, L. Salvo, Local tomography study of the fracture of an ERG metal foam, Adv. Eng. Mater. 15 (2013) 762-772.

[20] S. Youssef , E. Maire, R. Gaertner, Finite element modelling of the actual structure of cellular materials determined by X-ray tomography, Acta Mater. 53 (2005) 719-730.

[21] H. Toda, T. Ohgaki, K. Uesugi, M. Kobayashi, N. Kuroda, T. Kobayashi, M. Niinomi, T. Akahori, K. Makii, Y. Aruga, Quantitative assessment of microstructure and its effects on compression behavior of aluminum foams via high-resolution synchrotron X-ray tomography, Metall. Mater. Trans. 37A (2006) 1211-1219. 
[22] NIH National Institute of Health, Image J [in line]. Available on:

$<$ http://imagej.nih.gov/ij/ $>$.

[23] E. Maire, P. Colombo, J. Adrien, L. Babout, L. Biasetto, Characterization of the morphology of cellular ceramics by 3D image processing of X-ray tomography, J. Eur. Ceram. Soc. 27 (2007) 19731981.

[24] D.S. Metsger, M.R. Rieger, D.W. Foreman, Mechanical properties of sintered hydroxyapatite and tricalcium phosphate ceramics, J. Mater. Sci. - Mater. Med. 10 (1999) 9-17.

[25] J.H. Park, J.Y. Bae, J. Shim, I. Jeon, Evaluation of suitable porosity for sintered porous $\beta$ tricalcium phosphate as a bone substitute, Mater. Charact. 71 (2012) 103-111.

[26] S. Cai, G.H. Hu, X.Z. Yu, W.J. Zhang, Z.Y. Xiao, K.D. Yao, Fabrication and biological characteristics of $\beta$-tricalcium phosphate porous ceramic scaffolds reinforced with calcium phosphate glass, J. Mater. Sci. - Mater. Med. 20 (2009) 351-358.

[27] G. Bruno, M. Kachanov, Porous microcracked ceramics under compression: Micromechanical model of non-linear behavior, J. Eur. Ceram. Soc. 33 (2013) 2073-2085.

[28] E.C. David, N. Brantut, A. Schubnel, R.W. Zimmerman, Sliding crack model for nonlinearity and hysteresis in the uniaxial stress-strain curve of rock, Inter. J. Rock Mech. Min.52 (2012) 9-17.

[29] V. Cannillo, T. Manfredini, M. Montorsi, A.R. Boccaccini, Use of numerical approaches to predict mechanical properties of brittle bodies containing controlled porosity, J. Mater. Sci. 39 (2004) $4335-4337$.

[30] S. Deville, S. Meille, J. Seuba, A meta-analysis of the mechanical properties of ice-templated ceramics and metals, Sci. Technol. Adv. Mater. 16 (2015) 1-15.

[31] P. Miranda, A. Pajares, E. Saiz, A.P. Tomsia, F. Guiberteau, Mechanical properties of calcium phosphate scaffolds fabricated by robocasting, J. Biomed. Mater. Res. A 85 (2007) 218-227.

\section{Figures and tables}


Table 1: Values of $\mathrm{d}_{10}, \mathrm{~d}_{50}$ and $\mathrm{d}_{90}$ of the $\beta$-TCP powder before and after ball milling

Table 2: Values of effective Young's modulus and compression strength obtained from our compression tests and comparison with values from the literature

Table 3: Values of effective Young's modulus calculated from loading and unloading cycles

Fig. 1: Granulometric distribution of the PE beads measured by laser granulometry

Fig. 2: SEM images of: (a) macro PE spheres and (b) micro PE spheres

Fig. 3: (a) 3D visualization of the sample obtained from an image with a voxel size of $15 \mu \mathrm{m}$, (b) slice of a part of the sample with a voxel size of $15 \mu \mathrm{m}$, (c) the same slice with a voxel size of $3 \mu \mathrm{m}$ (local tomography) and (d) a magnified view of a zone of interest of the slice

Fig. 4: Relative density in slice profiles along the three main directions of the sample

Fig. 5: (a) Cell wall size and (b) pore size distribution of the sample measured by image processing granulometry [18] using a spherical structural element

Fig. 6: (a) SEM image of a polished section of a dense sample after thermal etching and (b) magnified view of $\beta$-TCP grains

Fig. 7: (a) Compression stress/strain curves corresponding to the successive loadings and to the test until rupture (black curve) and (b) magnified view of the beginning of the final stress strain curve showing the increase of stiffness in the linear part

Fig. 8: Loading and unloading cycles undergone by the sample. The loading curve corresponds to the first loading curve of the fig. $7 \mathrm{a}$.

Fig. 9: Slice perpendicular to the loading direction after the sixth loading illustrating the cracks propagation in the sample.

Fig. 10: Slice perpendicular to the loading direction after (a) the first loading and (b) the sixth loading. The red frames are magnified views of parts of the slice where the crack initiated and propagated. 
Figures

Fig. 1

Fig. 2

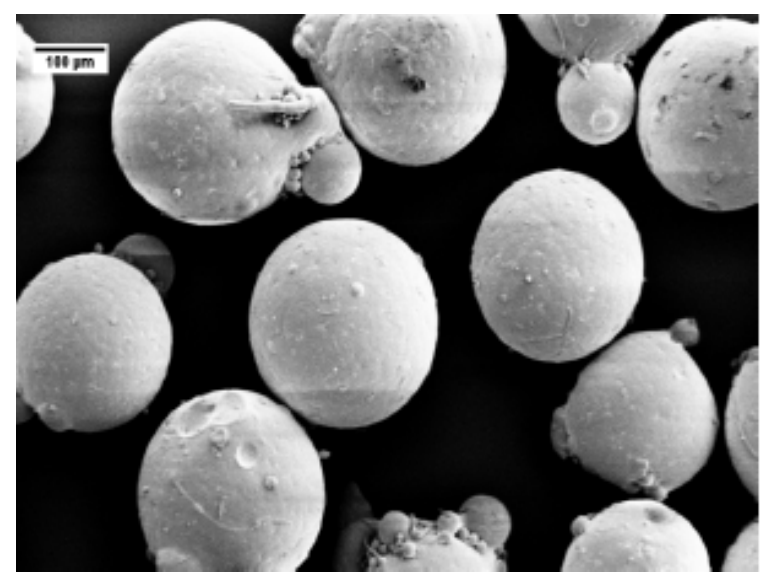

(a)

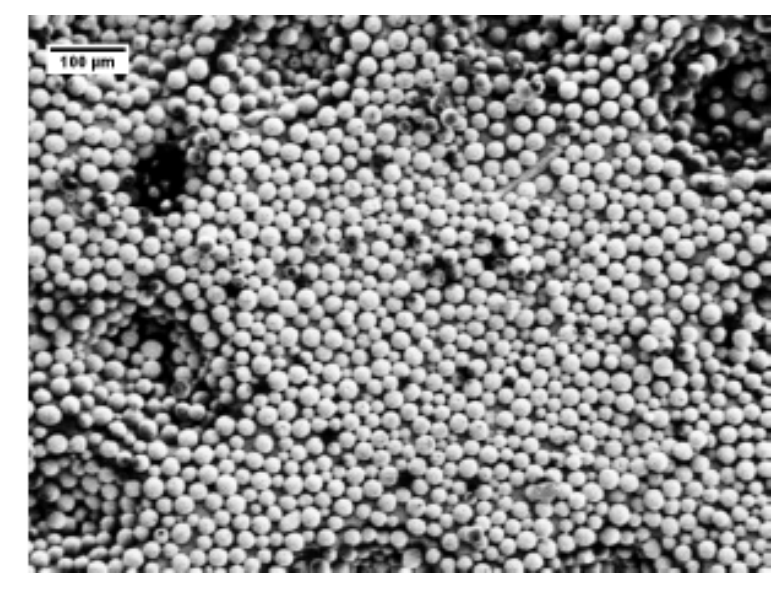

(b) 
Fig. 3

(a)

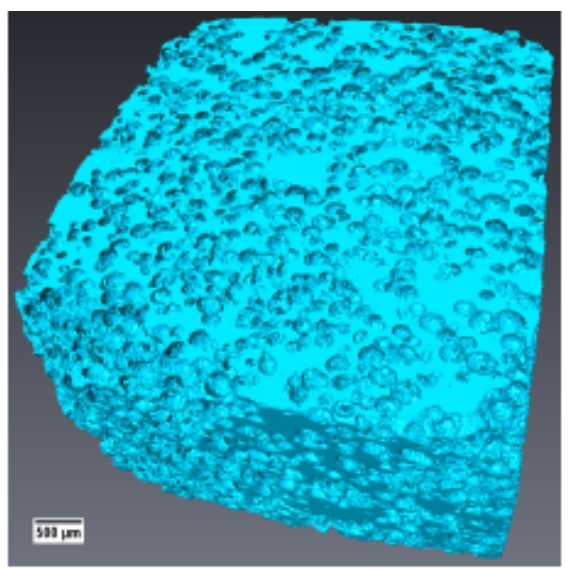

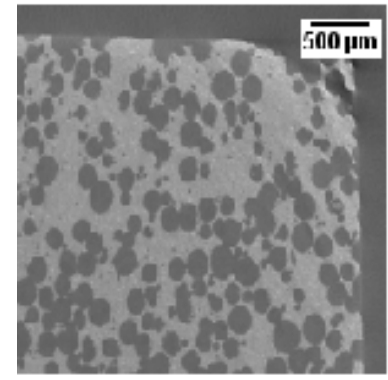

(b)

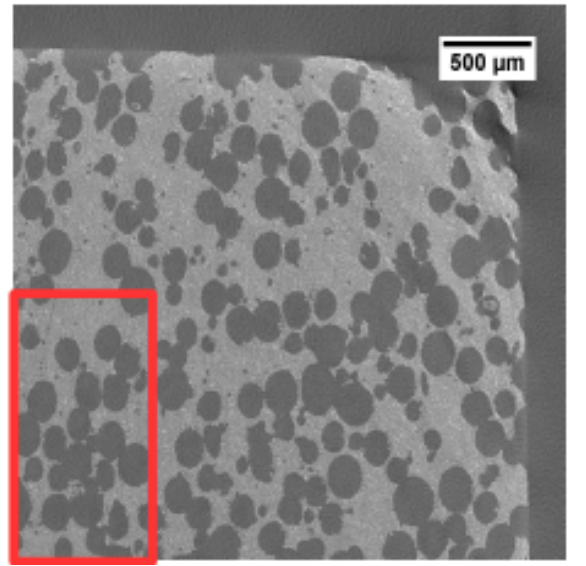

(c)

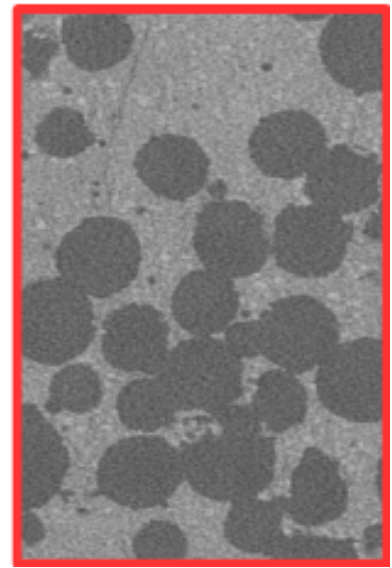

(d)

Fig. 4

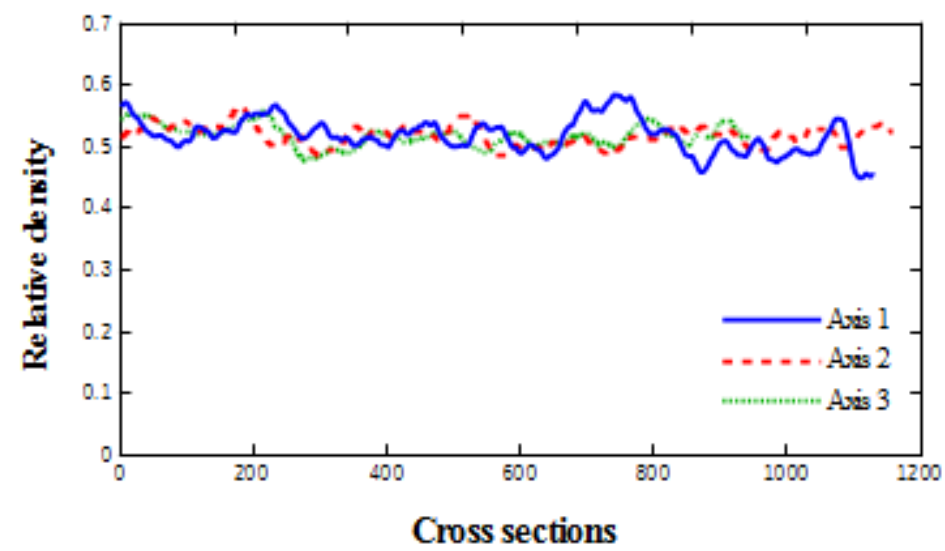


Fig. 5
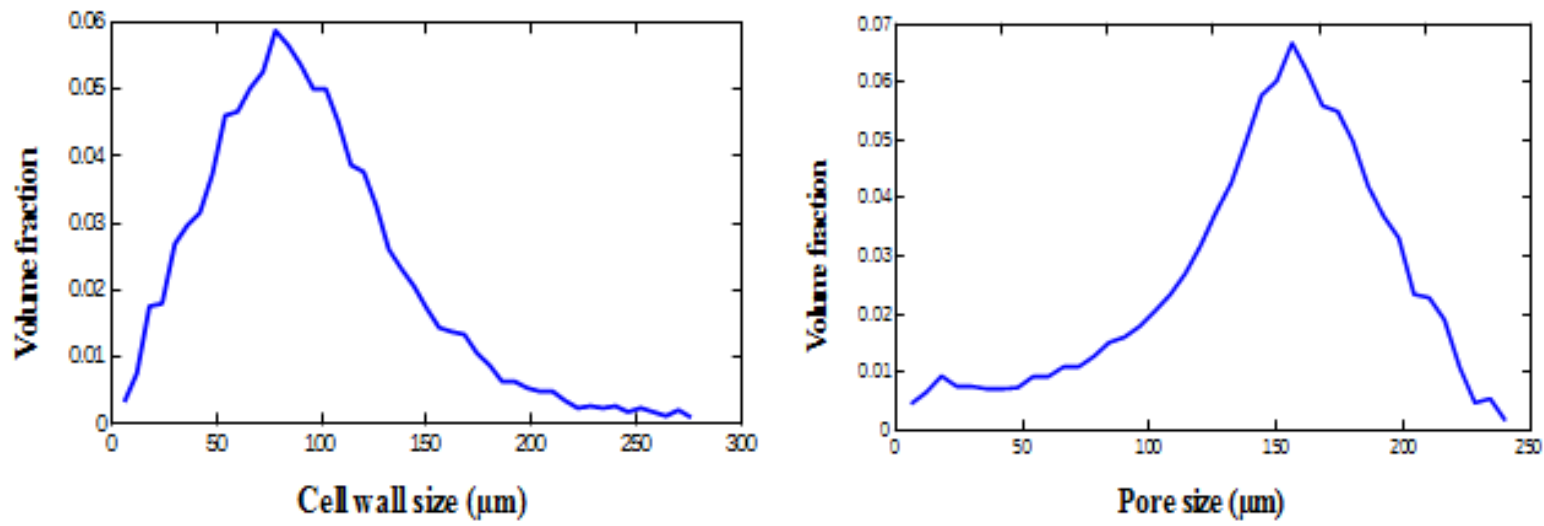

(a)

(b)

Fig. 6

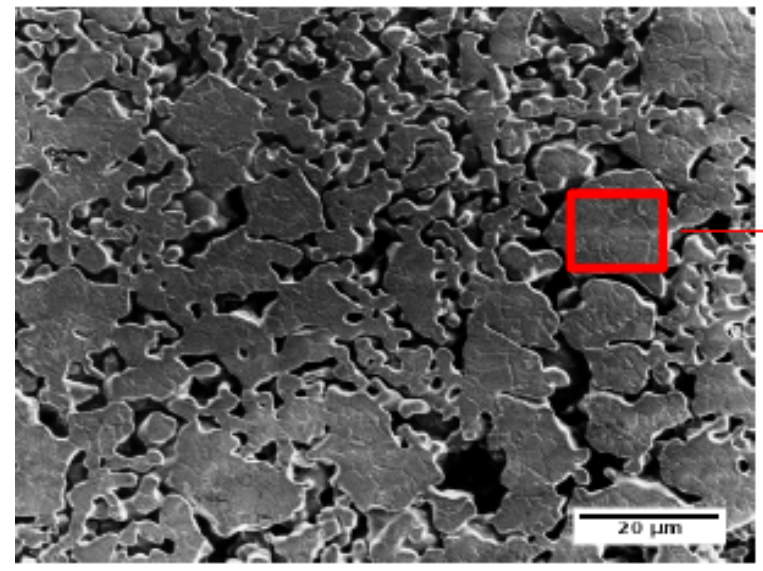

(a)

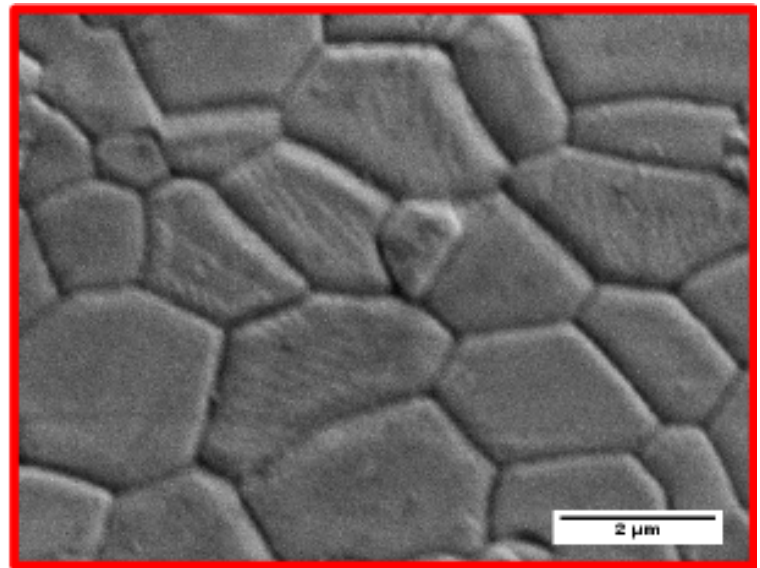

(b) 
Fig. 7

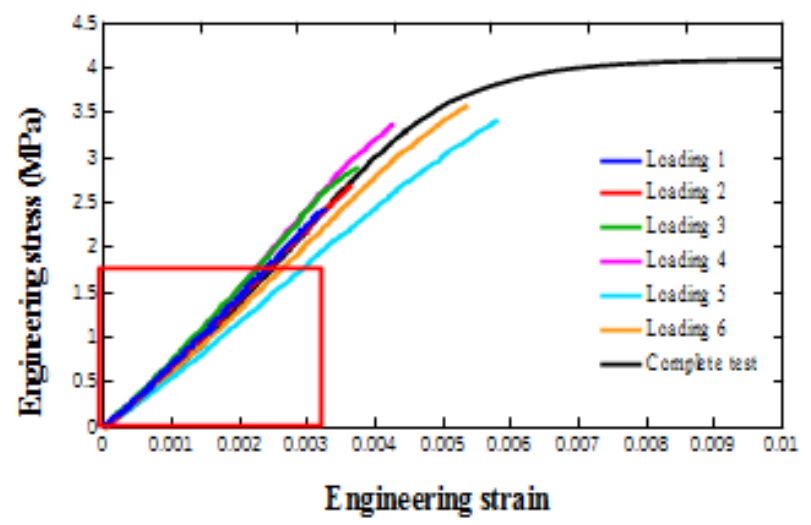

(a)

Fig. 8

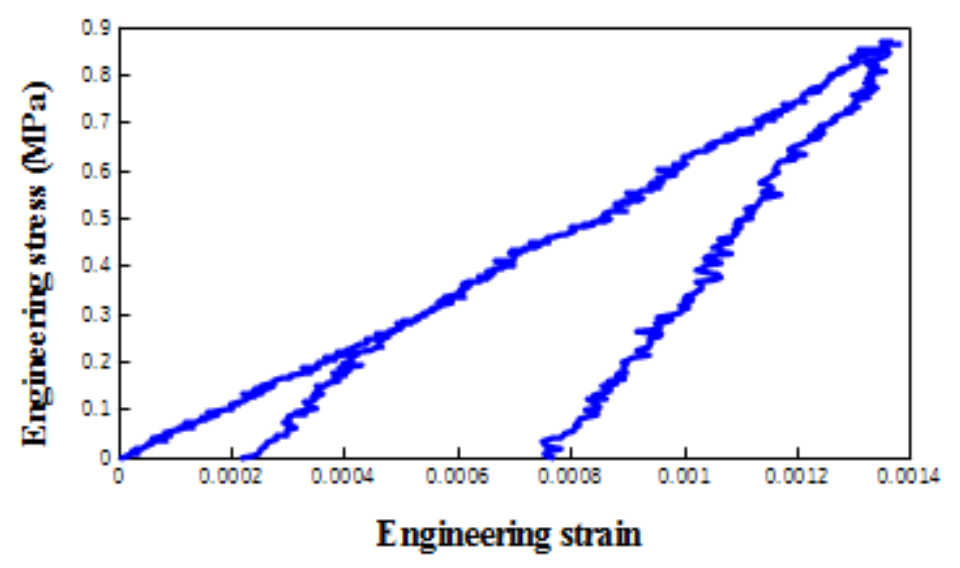

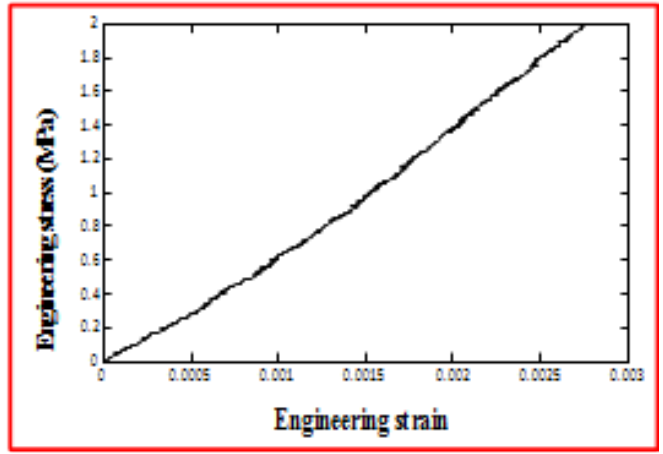

(b) 
Fig. 9
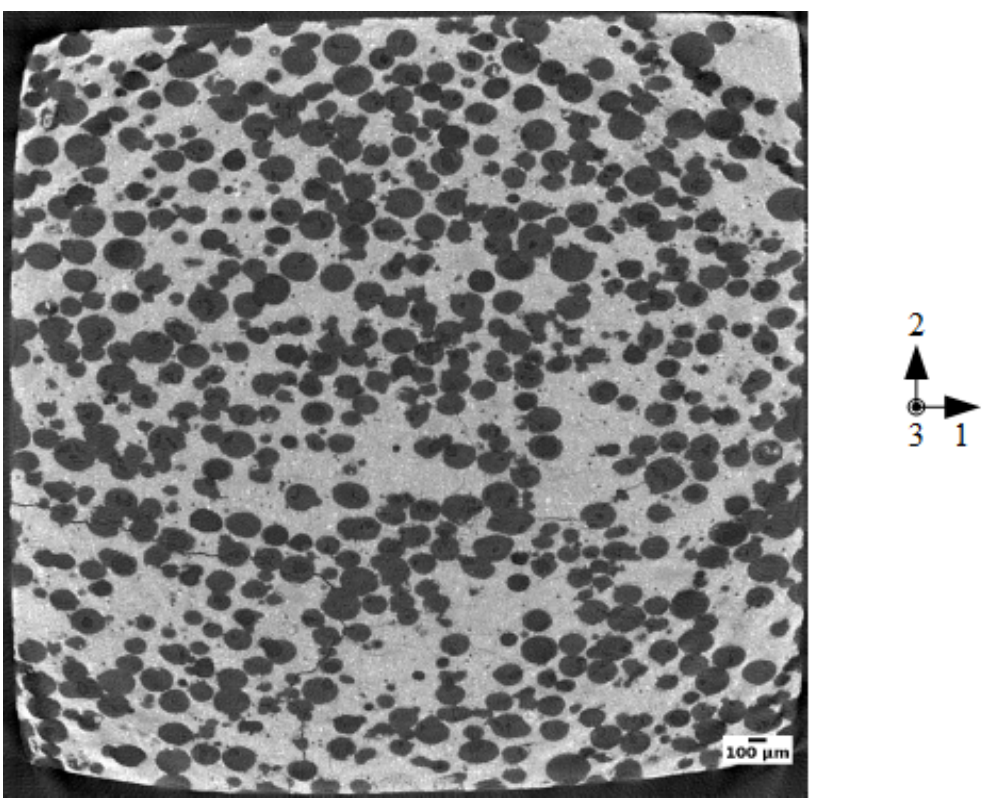

Fig. 10

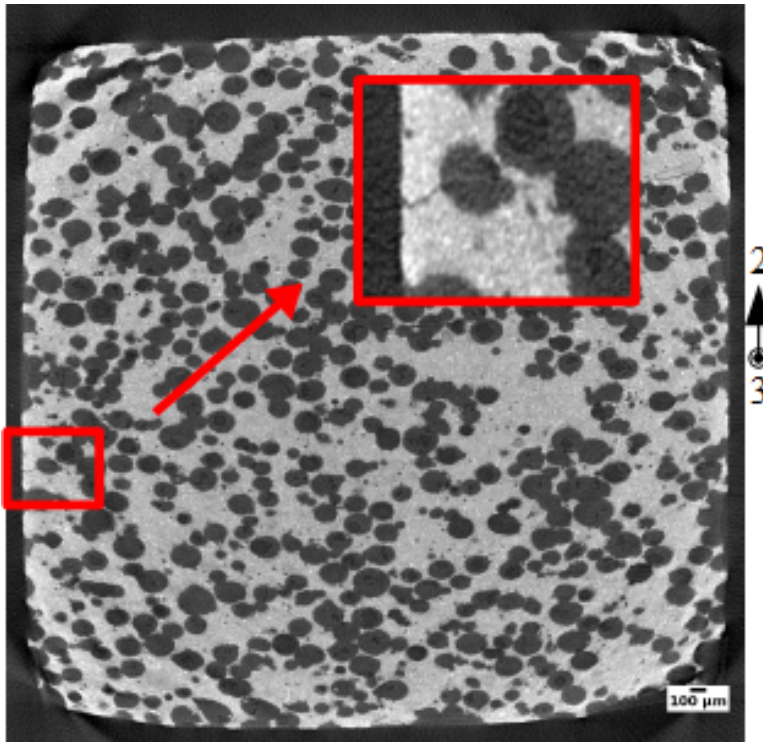

(a)

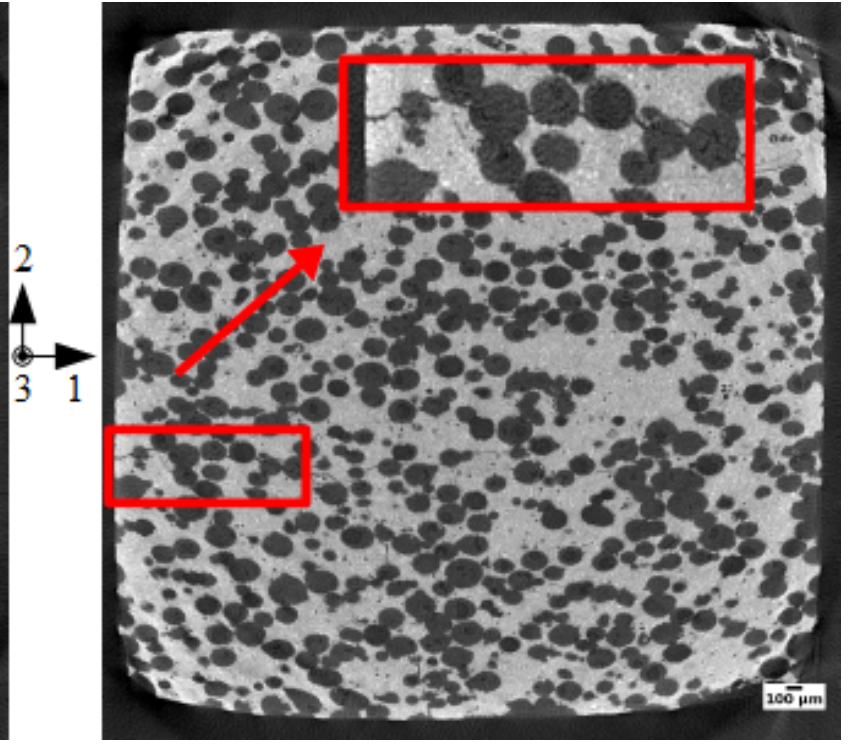

(b) 
